\title{
Automatic Recognition of Verbal Polysemy
}

\author{
Fumiyo FUKUMOTO * Jun'ichi TSUJII $\dagger$ \\ Centre for Computational Linguisties, UMIST \\ P.O.Box 88, Manchester M60 1QD, United Kingdom \\ E-mail fukumoto@ecl.umist.ac.uk tsuji@@cl.umist.ac.uk $\uparrow$
}

\begin{abstract}
Polysemy is one of the major causes of difficulties in semantic clustering of words in a corpus. In this paper, we first give a definition of polysemy from the viewpoint of clustering and then, based on this definition, we propose a clustering method which recognises verbal polysemies from a textual corpus. The results of experiments demonstrate the effectiveness of the proposed nethod.
\end{abstract}

\section{Introduction}

There has been quite a lot of research concerned with automatic: clustering of semantically similar words or antomatic recognition of collocations among them from corpora [Church, 1991], [Hindle, 1991], [Smadja, 1991]. Most of this work is based on similarity measures derived from the distribution of worels in corpora. However, the facts that a single word does have more than one meaning and that the distribution of a word in a corpus is a mixture of usages of different meanings of the same word often hamper such attempts.

The meaning of a word depends on the domain in which it is used; the same word can be used differently in clifferent domains. It is also often the case that a word which is polysemous in general is not polysemous in a restricted subject domain. In general, restriction of the suljject domain makes the problem of polysemy less problematic. However, even in texts from a restricted donain such as Wall Street Journal ${ }^{1}$, one enconnters quite a large number of polysemous words. In particular, nulike nouns, verbs are often polysemous even in a restricted subject domain.

Because polysomous verbs are usually also lighfrefuency verbs, their treatment is crucial in actual applicalions. Furthermore, because of their highfrequency, polysemous verbs tend to have a harmful influence on the semantic clustering of nouns, because semantic clustering of nouns is ustally performed based on their collocational belaviour with verlos.

* FURMO'TO is now at Department of Hectrical bingineering and Computer Science, laculty of Lingineering, Yananashi University. E-mai. lukumoto@skye.esi.yamanashi.ac.jp

${ }^{1}$ Wall Street Jommal was prepared by $\Lambda$ CI. (Association for Conputational linguistics' Jata Collection Initiative) in $199 \mathrm{~L}$.
Although polysemy is said to be widespread in language, the definition of polyseny is highly subjective. Polyseny can only be recognised by human intuition and different linguists often identify a different number of senses in the same word. In this paper, we first give a definition of polysemy from the viewpoint of clustering, and propose an overlapping clustering method which automatically recognises polysemous words. The results of experiments are also given to demonstrate the effectiveness of our method.

\section{Related Work}

Although there have been several attempts to extract scmantically similar words from a given corpus, few studies seriously deal with the problen of polysemy; of these, even fewer are based on real texts.

The techniques devoloped by Zernik [Zornik, 1991] and Brown [Brown, 1991] seem to cope with the discrimination of polysemy and be based on real texts. Zernik used monolingual texts which consist of about 1. million words tagged by part-of-speech. His method associates each word sense of a polysemous word with a set of its co-occurring words. If a word has several senses, then the word is associated with several different sets of co-occurring words, each of which corresponds to one of the senses of the word. The limitation of Zernik's method, however, is that it solely relies on human intuition for identifying different senses of a word, i.e. the human editor has to determine, by her/his intuition, how many senses a word has, and then identify the sets of co-occurring words (signatures) that correspond to the different senses.

Brown used bilingual texts, which consist of 12 million words. The results of Brown's technique, when applied to a French-English machine translation system, seems to show its effectiveness and validity. However, as he admits, the approach is linited because it can only assign at nost two senses to a word. More seriously, polyseny is defined in terms of translation, i.e. only when a word is translated in to two different words in a target language, it is recognised as polysemous. The approach can be used only when a large parallel corpus is available. Furthermore, individual seuses thus identified do not necessarily constitute single semantic units in the monolingual domain to which plansible semantic propertics (i.e. semantic restrictions, 
collocations, ete.) can be associated.

The defects of these two methods show that it is crn cial to have an appropriate definition of polysemy in terms of distributional behaviours of words in monolingual texts. The approach proposed in this paper focuses on this problem. Tike Brown's approach, our approach arlopts a relativistic view of polyseny. That is, a word is recognised as polysemous in ternes of other related words. However, while Brown's approach identities polysenous words in terms of related words of another language, we nse semantically similar words of the same language to identify polysemous words. Whether a word is polysemous or not depends on whether a set of other, semantically similar words exists whose distributional behaviours correspond to a subset of the distributional behaviour of the word.

Because the distributional behavion of a word is charaterised by its co-occurring words, the process of identifying such sibbsets essentially corresponds to the process performed mannally by the human editor in Zernik's approach.

The experiments in this paper use a corpus annotated only by part-of-speech but not structurally annotated. However, the clustering algorithn, which antomatikally recognises polysemous words, only assumes that words are semantically characterised by a vector in an $n$-dimensional space so that it can be applied to any dated salisfying this condition.

\section{Polysemy in Context}

The basic assumption of this work is the same as that made in previous corpus-based approaches, i.e. semantically similar words appear in a similau: context. Semantically similar verbs, for example, co-occur with the same nouns. The following sentences from the Wall Street Journal conpus show the point:

(sl) New York Times said it offered to buy the shares of pop radio corpl.

(s2) He may sell more shares in the open market or in private transactions.

It is intuitively obvions that buy and sell are semantically related and that the scmantic closeness of these two verbs is manifested by the fact that they co-ocer11 with the same noun shares. Wo can think of an $n$. dimensional space, ach dimension of which is associated with a specific: noun and in which a verl is assigneel a vector whose value of the $i$-the dinnension is the value of mutual information ( $\mathrm{mu}$ in short) [Church, 1991] between the verlo and the nonn assigned to the $i$-th axis. If the basic assumption is correct, then semantically sinilar verbs form a cluster in the space, and therefore, statistical clustering algorithens can be applied to vertb vector's in order to discover semantic classes of verlos.

IIowever, this straightforward method is often hannpered by the existence of polysemous words. The fol- lowing sentences show polysemous nsages of take.

(s3) In the past, however, coke has typically taken a miriority stake in such ventures.

(s3') Guber and peters tried to buy a stake in mgm in 1988.

(s4) That process of sorting out specifies is likely to take time.

(st') We spent a lot of tinke and money in buileling our group of stations.

(s5) People are quening at the door to take his product but he doesin't have the working capital to make the thing.

(s5) Goodyear used atwood trade redits to oltain chemicals and other products and services in the U.S.

We can make the following observations.

1. take and buy in (s:3) and (s3'), take and spend in (s4) and (s4), take and obtain in ( 85 ) and (s5') co-occur with the noun stake, time and product, respectively, and the verhs of each of these pairs lave alnost the same sense.

2. While certain usages of take have senses similar to buy, spend, and obtain, these three specific verbs have distinct senses and we hardly see synonymy among these verbs.

In the space spanned by the three axes, cach associated with stake, time, and product, take does not constitute a cluster with any of the three verlss. take co-occurs with the three nouns and hat high mat values with them, while buy, spend and olstain have high mu values only with one of the three nowns. Therefore, the distances betweren take and these three verbs are largo and the synonymy of take with them disappears.

In order to enpture the synonymy of take with the three verls correctly, one has to decompose the vector assigned to take into three component vectors, eacl of which corresponds to the three distinct usages of talke. The decomposition of a vector into a set of its component vectors recuires a proper decomposition of context in which the word occurs. Higure 1 shows the decomposition of the verls take in the thec-dimensional spaces. take1, take2, and take3 are the component vectors which collectively constitute the vector assigned to take.

For the sake of simplicity, we assume in the above that the three nouns characterise the contexts where the verb take occurs and, at the sanne time, each of them characterises a distinct usage of take. IIowever, in a general situation, a polysemons verb co-occurs with a large group of nouns and one has to divide the grouly of nouns into a set of subgroups, ach of which correctly characterises the context for a specific sense of the polysemous word. The algorithm has to be able to determine when the context of a word should be divided and how.

There are delstering algorithns, called overlapping clustering [Jardine, 1991], which allow an entity to be-. 


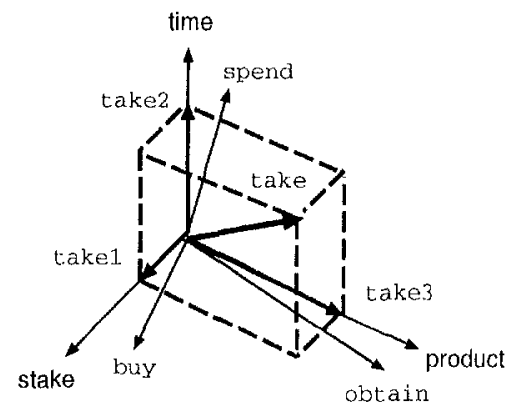

Figure 1: The decomposition of the verb take

long to more than one cluster. However, these algorithms assume that even an entity which belongs to more than one clusters is still a single entity. An entity belongs to several clusters because it can be seen from several different viewpoints. The same entity, for example, egg, can be seen as food, like bread, and as ingredients-of-food, like flour, at the same time.

However, as we saw in the above, polysemous verbs can be captured more naturally by seeing them as multiple entities, which happen to take the same surface form. take1, take2 and take3 are distinct entities (we call them hypothetical verbs in the following) with which different sets of nouns co-occur, and with which, therefore, different contexts are associated.

Therefore, unlike standard overlapping clustering algorithms, our algorithm explicitly introduces new entities when an entity is judged polysemons and associates them with contexts which are subcontexts of the context of the original entity. Our algorithm has two basic operations, splitting and lumping. Splitting means to divide a polysemous verb into two hypothetical verbs and lumping means to combine two hypothetical verbs to make one verb out of them.

\section{Measuring the Compactness of a Group of Verbs}

The algorithm should rlecide when a verb has to be split into two hypothetical verbs. The decision is based on a measure of the semantic compactness of a group of verbs. The semantic compactness of a group of verbs is a neasure which shows the degree of dispersion of the group in an $n$-dimensional space. The compactness of a group of verbs, $V G=\left\{v_{1}, v_{2}, \cdots, v_{m}\right\}$, is defined as follows.

1. Let $v_{i}$ be one of the verbs $v_{1}, \cdots, v_{m}$, and a vector assigned to $v_{i}$ be $\left(v_{i 1}, \cdots, v_{i n}\right)$. Earh $v_{i j}(1 \leq \mathrm{j} \leq$ 11) is computed by the following formula.

$$
\begin{array}{cl}
v_{i j}=m u\left(v_{i}, n_{j}\right) & \text { if } m u\left(v_{i}, n_{j}\right) \geq \alpha \\
0 & \text { otherwise }
\end{array}
$$

Here, $m u\left(v_{i}, n_{j}\right)$ is the value of mutual information defincd in [Church, 1991] between $v_{i}$ and $n_{j}$. $\alpha$ is a threshold value given in advance.

2. The centre of gravity of a group of verlos, $v_{1}, \cdots$, $v_{m}$, is the nean vector of the vectors assigned to the verbs, which is used to compute the dispersions of the inclividual verbs in the group. The centre of gravity $\bar{g}=\left(\overline{g_{1}}, \cdots, \overline{g_{n}}\right)$, and the length of it $|\bar{g}|$, are defined as follows.

$$
\begin{aligned}
\left(\overline{g_{1}}, \cdots, \overline{g_{n}}\right) & =\left(\frac{1}{m} \sum_{i=1}^{m} v_{i 1}, \cdots, \frac{1}{m} \sum_{i=1}^{m_{2}} v_{i n}\right) \\
|\bar{g}| & =\frac{1}{m} \sqrt{\sum_{j=1}^{n}\left(\sum_{i=1}^{m} v_{i j}\right)^{2}}
\end{aligned}
$$

3. The dispersion, $\operatorname{dis} p\left(v_{1}, \cdots, v_{m}\right)$, indicates the compactness of a group and is defined as:

$$
\operatorname{disp}\left(v_{1}, \cdots, v_{m}\right)=\sqrt{\sum_{i=1}^{m} \sum_{j=1}^{n}\left(v_{i j}-\bar{g}_{j}\right)^{2}}
$$

4. Let us think of two clusters of verlss, $A$ and $B$, which have the same degree of dispersions. If $|\bar{g}|$ of $A$ is larger than that of $B$, the absolute value of $m u$ calculated for $A$ is larger than that of $B$. This means that the alssolute probabilities of cooccurrences of each noun and the verbs of $A$ is larger than those of $B$; as a result, $A$ should be judged to be semantically more compact than $B$. Therefore, the dispersion of (3) is normalised as:

$$
\operatorname{disp}_{\text {nor }}\left(v_{1}, \cdots, v_{m}\right)=\frac{\operatorname{disp}\left(v_{1}, \cdots, v_{m}\right)}{|\vec{g}|}
$$

5. dispnor of (4) is proportional to the number of verbs. This means that a cluster of a greater number of verbs tends to be judged to be less compact than those of a smaller number of verbs. Therefore, the dispersion of (4) should be further normalised to compensate the effect of the number of verbs in a group. This normalisation is done by least square estimation. The result is (5), which will be used to measure the compactness of a group of verbs.

$$
\operatorname{Com}\left(v_{1}, \cdots, v_{m}\right)=\frac{d i s p_{n o r}\left(v_{1}, \cdots, v_{m}\right)}{(\beta * m-\gamma)}
$$

$\beta * m-\gamma(\beta=0.964, \gamma=0.495)$ is a coefficient that is empirically determined by least square estimation ${ }^{2}$.

In the following, we use (5) as the value which shows the compactness of a group. A group with a smaller value of $(5)$ is judged semantically more compact.

\footnotetext{
${ }^{2}$ In this case, we set $\alpha$ in (1) equals to 3.0 .
} 


\section{Clustering Method}

In this section, we present onr chustering algorithun. Wo first explain the operations of splithing and humping. J'hen. we show the flow of the algorithen and explain low the whole algorithm works.

\subsection{The Basic Idea}

The chustering algoritlen proposed in this paper be-

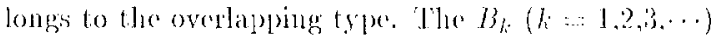
wethod, proposed by fardine, is one of the typical orerlapping chestering algorithus [Jandinc, 1991]. The essential difference between ont algorithm and the $B_{k}$ wecthod is that our algorithem explicitly introduess a couclition when an entity (a verb) shonld be split and assigned to several dusters. In our method. whether a rerlo " has two senses or not is judged by comparing the semantie compacturess values of groups of verlos to lo produced. That is, there are possibilitiess of creating the following thee chusters:

$$
\begin{array}{r}
\left\{u_{1}, u_{1}\right\},\left\{u_{2}, u_{2}\right\} \\
\left\{u_{1}, u_{1}, u_{2}\right\}
\end{array}
$$

where $e_{1}$ and the in (6) are new. hypothetical rerbs which correspond to two distinct sellses of the sanke verle, a. Thesse two newly introduced rerlos atre supposere to appear in diflerent contexts. 'l'heir contexts are actually hypothesised by dividing the set of nombs 1. hat co-oceur with the verber into two distinct sats of nonus. This clivision of the context of the original redh is hypothesised based on the set of nombs that

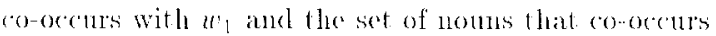
with $w \%$.

\subsection{Splitting and Lamping}

The operations of splitting and lumping are defined as follows:

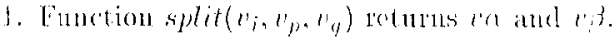

$\because$ is a rerb whose coordinate in an $n$-rlinemsional

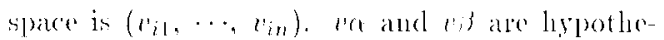
sised verbs whose coordinates in the m-dintensional space are made from the cootlinates of the original rests "i by clividling the set of nomes that coocene rvith $1 \%$ into two distinct sets. The division is mate in terms of two sets of momes: one is the

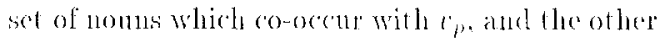
is the set of nouts which co-ocerter with "y.

$$
\begin{aligned}
& \text { split }\left(l_{i}, l_{p}, l_{4}\right) \quad=: \quad(10,1,4) \\
& \text { where } \operatorname{Com}\left(r_{i}, r_{y}\right) \leq \operatorname{Com}\left(n_{i}, c_{p}\right)
\end{aligned}
$$

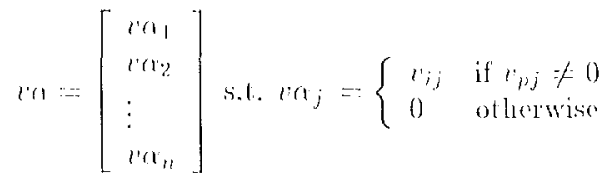

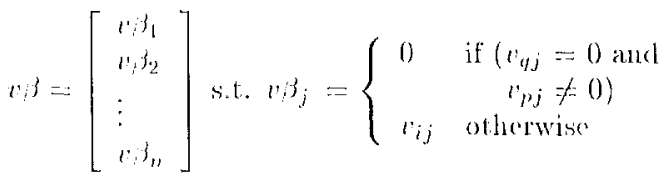

Note that if the nom associated with the dimen sion $j$ which co-ocecurs with $r$; also co-ocentes with both of $e_{p}$, and $r_{4}$, the ralues of the $j$-t he dimension

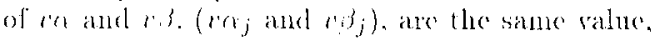
i.e. the value of the mu between the notur assoriated with the $j$ th climension and e; Futhermote. if the nom associated with the climension $j$, which co-oceruss with "i, doces not co-ocent with both "p and ${ }^{\prime}$, the value of the mu between the nonuts as sociated with the $j$-the climension and $\theta_{t}$ is set to the values of the $j$-the dimension of ris. Here. we call this value the surplus value. We reoall that the compracturess value of a groule of $"$; and $v_{q}$ is smaller than that of "i and "p. This means that the former is more compact than the latter. If the surphlus vilue is not set to both en aldel ras, the group of as ancl te is more compract than that of ra and $\%$. Cherefore, in order to make wer and is as syumetrical as possible, the surplus value is set 10103 .

2. Funetion lamp(en, wis) has the opposite effece of the function splif( $\left.v_{i}, c_{p,}, c_{4}\right)$, i.e. it merges en ancl b. Function lump(en. aj) returns $n_{i}$.

$$
\operatorname{lump(ln,1;\beta )}=\because \quad r_{i}
$$

$$
n=\left[\begin{array}{l}
r_{i 1} \\
r_{i 2} \\
\vdots \\
r_{i n}
\end{array}\right] \text { s.t. } v_{i j}= \begin{cases}1 n_{j}+v \beta_{j} & \text { if } n_{j} \neq u_{1} j_{j} \\
n n_{j} & \text { otherwise }\end{cases}
$$

\subsection{Flow of the Algorithm}

Given a group of rerits. $\|_{1}, l_{2}, \cdots, c_{m}$. the algorithm produces a set of semantic chusters, which are ordered

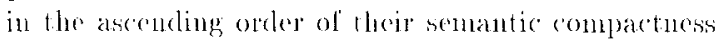
values. If $r^{\prime}$ is non-polysemonts. it bolongs to at least one of the resultant semantic clusters. If it is polysenous, the algorithm splits it into several hypothetical vertse and cacth of them belongs to at least one of the semantic cluster's. Thlo flow of the algorithun is shown in Figurese 2.

As shown in lignes 2, the algorithm is composed of three proceclures: Make-Initial-Cluster-Set, MakeTemporary-Cluster-Set and Recognition-of-Polysemy.

\section{Make-Initial-Cluster-Set}

'The procedure Make-Initial-Cluster-Set produces all possible pairs of retbs in the input with their scmantic compractuess values. The result is a list 


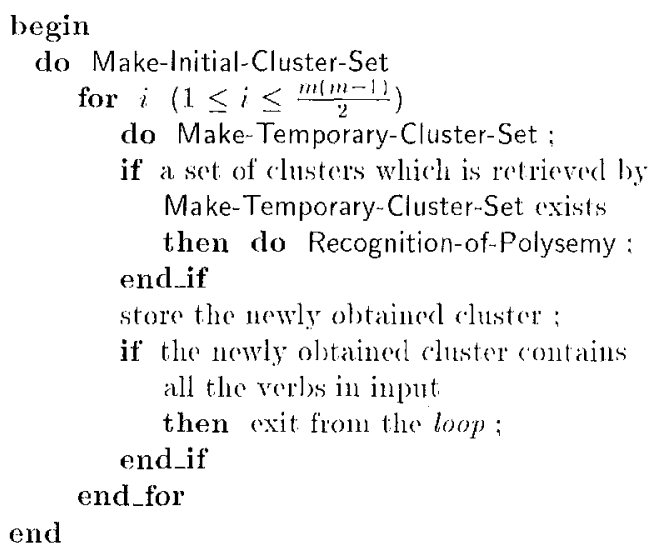

Figure 2: Tho flow of the algorithun

of pairs which are sorted in the ascending order of their seminutic compactuess values. The list is callod ICS (Initial Cluster Sot). ICS contains $\frac{m(m-1)}{2}$ pairs. Tn the EOR-loop in the algorithn, a pair of verlos is retricyed from ICS, one at cach itcration, and passed to the next two procedures.

\section{Make-Temporary-Cluster-Set}

The procedure takes two arguments: The first atgument is a pair of verbs from ICS and the second one is a set of chusters (CCS - Created Cluster Set). CCS consists of the chesters which have been created so far. When the algorithm terminate's, CCS is the output of the algorithu. MakeTemporary-Cluster-Set retrieves the clusters from CCS which contain one of the verbs of the first argument (a pair from ICS). The clusters thus retrieved from CCS are passed to the next procedure for further consideration. If the ere is 110 CCS which contains one of the verles of a pair from ICS, a pair of verbs from ICS is stored in CCS als a nerry ol ol tainerl chister.

\section{Recognition-of-Polysemy}

This procedure, which recoguises a polysenous verb, also takes two argunents: the pair of verbs from ICS and a set of clusters retrieved lyy MakeTemporary-Cluster-Set.

We recall the eliscussion in section 5.1. Let $\{u$, $\left.u_{1}\right\}$ be the pair of verlos from ICS and $\left\{u, u_{2}\right\}$ be one of the clusters of the second argument, i.e. the clusters so far obtained which contain one of the verbs, " in the pair. We lave to determine whether the verb $v$ has two senses. which colresponds to $w_{1}$ and $w_{2}$, respectively. This is cletermined by comparing the semantic compactness values of the three clifferent clusters shown in (6) and (7). The splitting function (8) is applies to $w, w_{1}$, and $w_{2}$ and produced newly hypothetical verlos, $n_{1}$ and $v_{2}$ The lumping function (9) is applied to $\nu_{1}$ and $v_{2}$ and makes one verth $v$ out of them. If both of the scmantic compartuess values of each set shown in (6) are smaller than a set shown in (7), the sets (6) are selected, otherwise, (7) is solected and stored in CCS as a newly obtained reluster.

If the newly obtained cluster does not contain all the verlos in input, the next pair of verlos is taken from ICS. ancl then the whole process is repeated.

\section{Experiments}

Wo have conducted two experinents. The first ex periment is concerued with the chustering technique and with verifying the effect of the propesed method. The second experiment is conducted to see how various part-of-speech pairs affect the clustering results.

\subsection{Data for the Experiments}

The corpus we have nesed is the Well Street Journal which consists of $2,878,688$ ocenrences of part-ofspeech tagged words [Churede, 1991], 73,225 different. words. From this corputs, we obtained 5,940,193 word pairs in a window size of 5 words, 2,743,974 different word pairs.

26 gromps of verbs were 1 sed in the experiments, 108 verl) tokens with 56 different original form of verbs. These groups contain 10 different polysonons verbs. The groups of rerbs are divided into two clifferent types, "typel' ancl "trper'; 'typel' is a set of verbs containing one or nore polysemons verbs, and 'type?' does not contain any polysemous verbs. Each group is composed of 3 to 10 diflerent verlos. The selection of verlas of 'type1' was made with the intention of processing verbs with wide nsages, as identitied in the Collins dietionary and thesantrus [MeLeod, 1991]. Thern, a number of synonyns of the chosen verbs were selected from the thesaurus. 'The clustering allalysis is applied to "ach group of verbs. The same corpus and the groups of verbs are used thenghout the experiunents.

\subsection{Experiment-I}

In Experinent-I, we nescel verb-nonn paiss, i.e. we assnme an $n$-climensional space. in which a verb is assigned a vector whose value of the $i$-the climension is the value of mu between the verb and the nom assigned to the $i$-the axis. This is becatese, in the small winklow sizes, the semantic relationships between these two worels might be cluite strong, especially those between a verb and its object which permits the effective recognition of verbal polysemy. The inflected forms of the same nowns and verbs are treated as single 11 its. For 'xample, "tinte'(nomn, sing'nlar) and 'tintes'(noun, plual) are treated as single muits. We obtained 228,665 different rerb-nom pairs from 2,743,974 and from 
these, we selected 6,768 rlifherent rerb-10om pairs. 701 different valles and 1,796 nonus on condition that fro. fuencics and mu are not low $\left(N_{x y} \geq 5, m u(x, y) \geq 3\right)$ to permit a reliable statistical analysis and usect them iu the "xperinent". The results are shown in Table 1.

Talshe 1: The results of Experinent-

\begin{tabular}{|c|c|c|c|}
\hline & grouts & contert & incorrect \\
\hline typel & 11 & 9) & 5 \\
\hline typez & 12 & 9 & 3 \\
\hline total( $(1 / 1)$ & $2 \overline{6(})$ & $18(69.2)$ & $8(30.8)$ \\
\hline
\end{tabular}

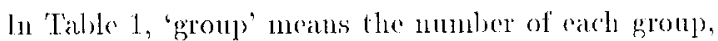
type] and types; 'correce' means the number of groups of verbs which are clustered correctly: incorrect nerans that they are not. Figure 3 shows carle salnHe of the results, i.e. type1-correct, type2-correct. type1-incorrect, and type2-incorrect. Fach valuc in Figure 3 shows the walue of the scmantic conepartuesis of a gromp of verlus.

In Figure 3, nucler the loading type1 correct, wo (an see that "take' is recognised ats a polysemots verls and has three different sensess, spereld", buy", and obtain'. In a sinilan way, "lose" has two cliflement semses, "end" and 'open' and scmantically close verlss are grouped together. Under the heading type2 correct scmationly similar verlss are gromper 10 gether. Ifowever, tuster the hearling type 1-incomect 'laver' is incorrectly recognised as a non-polysemons rerb; also moler the heading type2-incorrect come" is incorrectly recognised as a polysemous verb.

\subsection{Experiment-II}

Wo have conducted an experiunent using the varions prats-of-sperede shown in Talshe 2.

Table 2: The type and the number of pains

\begin{tabular}{|c|c|c|c|c|}
\hline$x-y$ & pair(1) & $\operatorname{lngir}(2)$ & $x$ & $y$ \\
\hline 11011n-v(1) & 250,732 & 0,420 & 1,993 & 505 \\
\hline rerb-aklyerl) & 23,248 & 1.200 & 250 & 320 \\
\hline adrerlevesh & 35,146 & $900^{\circ}$ & 16.3 & $3 \pi 7$ \\
\hline verb-preposition & 29.658 & 3.197 & 1.338 & 58 \\
\hline
\end{tabular}

Lin Table $2, x-y$ shows the type of part-of-speech pait of $d^{\prime}$ and $y$ in this order, where $r$ and $y$ ane the partof-speech of the words. pair(1)" shows the numbere of different part-of-speech pairs from $2.743,97$ and 'pair(2)' shows the number of different pattof-specerh pairs on condition that frecpuencies and ma ale $N_{x y} \geq$ 5. $m \cdot u(x, y) \geq 3 ; x$ and $y$ show the mumber of clifferent word. We used these in Fxperinent-II. 'The results are shown in Thable 3 .

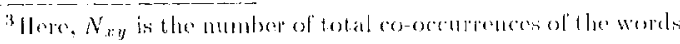
a amb y in this order in a winclow.
Table 3: 'The results of Lxperinent-II

\begin{tabular}{|c|c|c|}
\hline$x^{2}-y$ & $\operatorname{correct}(\%)$ & incorrect $(\bar{y})$ \\
\hline $1101111-\mathrm{r}(\mathrm{p})$ & $10(38.5)$ & $16(61.5)$ \\
\hline v(rb)-alverb & $5(19.2)$ & $21(80.8)$ \\
\hline adsorb-vals & $6(23.0)$ & $20(i i .0)$ \\
\hline reply-preposition & $6(23.0)$ & $20(77.0)$ \\
\hline
\end{tabular}

\section{Discussion}

In Experinent- $\mathrm{f}$, described in the previons section, 18 ont of 26 grones of verbs are analyed correctly and the poreentage attains $69.2 \%$ in all. Howevere as shown in 'Table 1, there are 8 groups which could not be recognised correctly. The cresors are dassitied into two types: 1 . Eirors of recognition of polysemons verbs als noth-polysemons ones; and 2. Jistors of recognition of non-polysemons verbes as polysemous ones. The munber of groups classified into each errer type

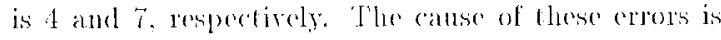
that ro-ocentring nom shased by wo verbs secoll to be slanted in these datat lor example, observing the "orpus, we cau see that leatre has at least two semests. 'retire" and "renain'. The following senteness are lrom the Wall Strest Jommal.

(s6) Kaplate left his joh at warner-lambert.

(s6) Alout 12\% bave retires from a full-time joll.

(si) They can erent leave a sticly problem, in the form of higher brokerage comminissions.

(si) but remain as serious problem.

Howerer. type1-incorrect in Fighere 3 shows that "leave is incorrecly recognised as a non-polyscmons verb. This creror was ansed loy the fact that the value of the semantic compartuess of retire and rematin was smallen than that of any other pair of worts and by the fare that the cardinality of as set of nomes which co-oceur with 'retire" and 'remain' is largere than than of any other pair of worels. Wr proxisionally ronedude that the use of verb-nom pairs aloue is not appropriate for all the groups of verlss.

In Experiment-Il. the overall tesults ale not as good as those of lixperiment-I. Howerer, we conkl observe sone interesting characteristics. Wancly, some groups which could not be andyesed correctly by neing vert)noun pairs conld be analysed (ondectly by using rert). adverh pairs ol verb-preposition pairs. The result.s show that 3 out of 8 groups surle als type1-incorrect in Figure 3 which were incorrect in Experinent-1 could ba analysed correctly by nsing verb-adverb pairs. Also. an ather 3 gromes such as type2-incorrect could be analysed correctly by using verb-preposition pais. Wo

\footnotetext{
"Wo do not comider luere general errors of semantic clus-

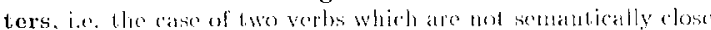

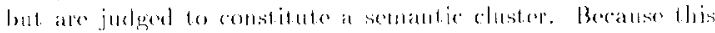

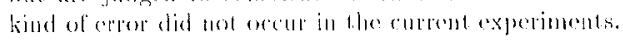



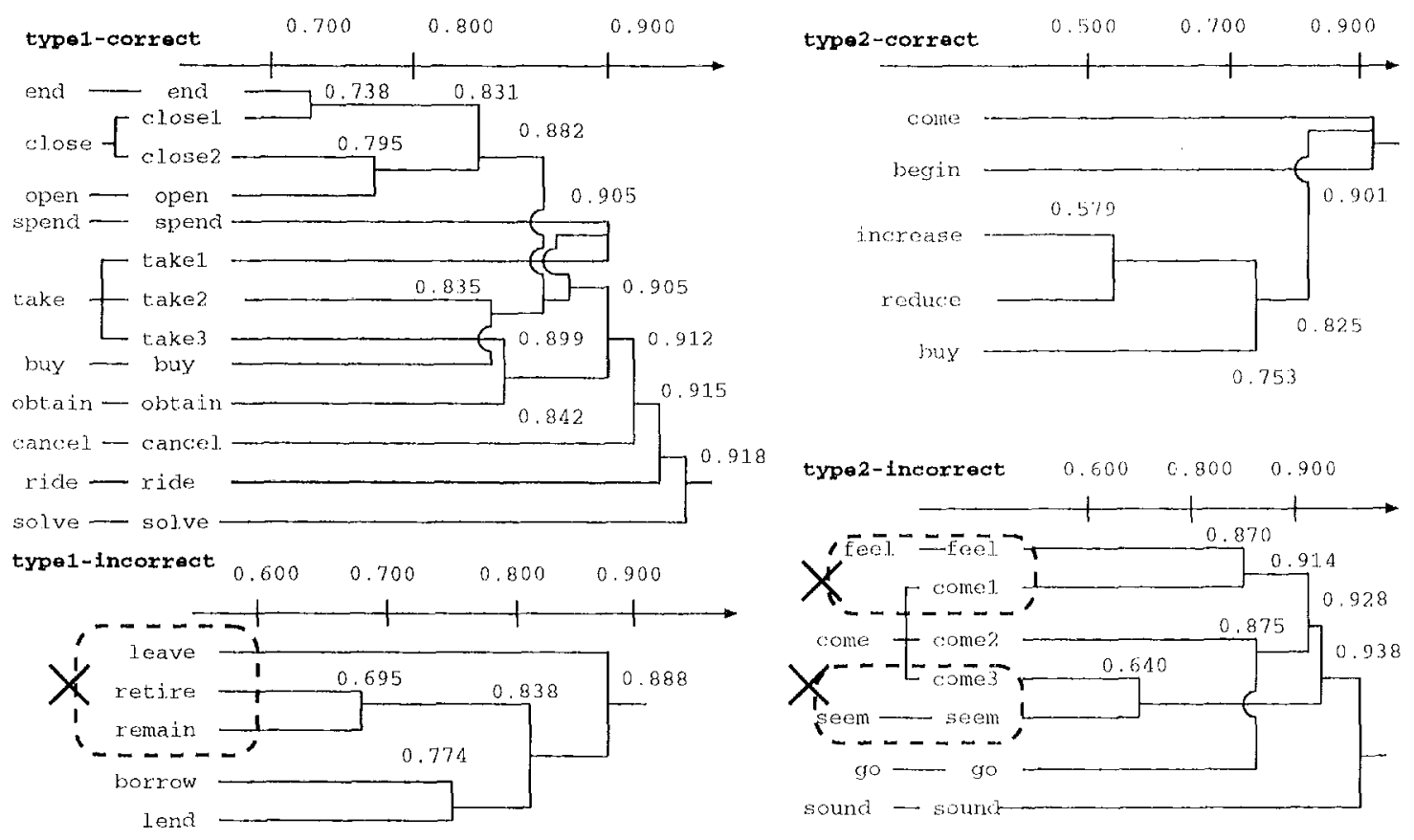

Figure 3: The results of the clustering analysis

(an therefore expert that we may be able to obtain more ancurate cluster's by neerging these three linds of part-of-speech pairs into one langer set. Because these thee different pairs show distinet chanacteristics of contexts in which a verb appears. Wo have been conducting more experiments on these.

\section{Conclusion}

Wo have given a definition of polyseny from the view point of clustering, and proposed au overlappling clustering mothod which automatically recognises verbal polysemies from a textual corpus. The significant fonture of our approach is that every separate meaning of a word is recognised in terms of other words that appear in the corpus. Whether a word is polysemons or not depends on wherher a set of other words exists whose usage corresponds to one of the neminings of a polysemons word. As a result, onr method can aroid human intuition in the judgement of distinct word nucanings and thus, hunnan intervention.

The results of the experiments clemonstrate the applicability of automatic metlod of recognition of polysemous verlss. We have conducted more experiments by changing parameters such as the threshold values for frecuencies $\left(N_{x y}\right)$ and mu $(m u(x, y))$ in oreler to sec how these paraneters affect the perfotmance of the 'hustering algorithm. Wo have also exteneled our technique to the disambiguation of word senses. We hope foreport these results soon.

\section{References}

Church. Kenneth W. of al. 1991, Using Statisties in Lexical Analysis. Lexicul nequisition: Raploiting on-line resourees to build a lexicon. (Zernik Uri (cd.)), pages 115164. Loudon, Lawrenes Fill anum Associates.

Hindle Donald. 1990. Nonn classification from predicateargunent strustures. In 28 th Amnthal Meeting of the Association for Comprtational Linguistices, pages 268 275. Pittshurgh, Penusylvania. Association for Comprntational Linguisties, Morristown. New Jersey.

Smadja, Frank A.. 1993. Retricving Collocations from Text: Xtract. In Computational Linguistices, panges 1431 \% $19(1093) 1$.

Zemili Uri. 1991. 'Jianin vs. Train2: Tagging Word Scuses in Corpus, Lexical accutustion: Explovting on-line resources to build a lexicon. Lin Zornik(El.). pages 91-112. London, Lawrence Brlbanum Associate's.

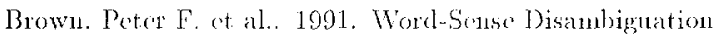
Using Statistical Mothods. In Proce of the 29th Ammal Mecting of the ACL pages $26+270$.

Jardine N. and Silson R., 1968. The construction of hicrarchic and non-hicmardic classifications. In Computer Jourual, pages 17\%-184.

Church, Kenuet $]_{2} W$. 1988. A stochastic parts progrannuc and nown phraser for unrestricted text. In Proce of the 2nd conforence on applied natural language processing, pages 136-1.43.

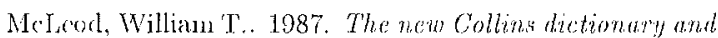

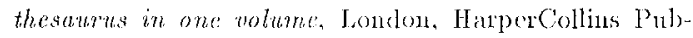
lisllets. 